\title{
FORMULATION, OPTIMIZATION, CHARACTERIZATION AND IN VIVO ANTI-ULCER ACTIVITY OF ESOMEPRAZOLE MAGNESIUM TRIHYDRATE GASTRORESISTANT MICROSPHERES
}

\author{
KRUTIKA SAWANT, MITALI PATEL, JITEN PATEL, PIYUSH MUNDADA \\ Drug Delivery Research Laboratory, TIFAC Center of Relevance and Excellence in NDDS, Faculty of Pharmacy, Shri G. H. Patel Pharmacy \\ Building, Donor's Plaza, The M. S. University of Baroda, Fatehgunj, Vadodara 390002, Gujarat, India
}

Email: dr_krutikasawant@rediffmail.com

Received: 28 Sep 2016 Revised and Accepted: 24 Nov 2016

\begin{abstract}
Objective: The objective of the present investigation was to prepare gastro-resistant microspheres of esomeprazole magnesium trihydrate (EMT) to prevent its degradation in the acidic environment of the stomach and enhance its bioavailability via intestinal absorption.

Methods: EMT loaded gastro-resistant microspheres were prepared using hypromellose acetate succinate (HPMCAS) as the gastro-resistant polymer by 'non-aqueous solvent evaporation' technique. A 3-factor 3 level factorial design was used to optimise EMT: HPMCAS ratio, the concentration of Span 80 and stirring speed with respect to percent entrapment efficiency and particle size. Further characterization was carried out using scanning electron microscopy (SEM), differential scanning calorimetry (DSC), In vitro release study and In vivo anti-ulcer activity.

Results: Fourier transform infrared (FTIR) study indicated compatibility between drug and polymer. DSC study revealed that the drug was molecularly dispersed in the polymer. The optimised batch showed $49.63 \pm 1.23 \%$ drug entrapment and $170.12 \pm 3.36 \mu \mathrm{m}$ particle size. SEM study showed that microspheres were spherical in shape. In vitro drug release study showed only $4.28 \pm 1.23 \%$ drug release in simulated gastric media in 2 $\mathrm{hr}$ and $93.46 \pm 1.20 \%$ release in simulated intestinal media after $1 \mathrm{hr}$ from the optimised batch.
\end{abstract}

Conclusion: Results of in vitro release studies indicated the gastro-resistant nature of the developed microspheres. In vivo anti-ulcer activity demonstrated that EMT loaded microspheres were able to significantly reduce ethanol-induced ulcer formation in rats' stomach as compared to the aqueous solution of EMT. So it can be concluded that the developed gastro-resistant microspheres of EMT prevented drug release in the stomach which would lead to a significant improvement in its bioavailability through enhanced intestinal absorption.

Keywords: Gastroresistant, Microspheres, Design of experiment, Factorial design, HPMC acetate succinate, Ulcer-index

(C) 2017 The Authors. Published by Innovare Academic Sciences Pvt Ltd. This is an open access article under the CC BY license (http://creativecommons.org/licenses/by/4. 0/)

DOI: http://dx.doi.org/10.22159/ijpps.2017v9i1.15437

\section{INTRODUCTION}

Oral route is one of the most preferred and convenient routes for administration of the drug because of its ease of administration and production, greater flexibility in dosage form design and low cost of such a system. About $40 \%$ of drugs are poorly water soluble and/or have limited membrane permeability which provides an opportunity to develop an alternative formulation to overcome drawbacks. Thus, a number of the controlled release systems have been developed for oral administration. The growing interest in controlled drug delivery is due to its benefits like increased patient compliance due to a reduction in unwanted side effects and dosing frequency $[1,2]$.

There are various approaches to target a specific site in a sustained/controlled release fashion. The single unit system has the disadvantage of being removed with chyme. In comparison to single unit systems, multiple unit system has marked advantages as it spreads over a large area and avoids exposure of high concentration of drug to the mucosa. The risk of dose dumping is minimised [3]. Microspheres are small spherical particles, with diameters in the micrometre range (typically $1 \mu \mathrm{m}$ to $1000 \mu \mathrm{m}$ ). They are sometimes referred to as microparticles [4].

Esomeprazole magnesium trihydrate (EMT), the S-isomer of omeprazole, irreversibly inhibits the gastric parietal $\mathrm{H}+/ \mathrm{K}+\mathrm{ATPase}$ which is involved in $\mathrm{HCl}$ production in the stomach. It is used in the treatment of peptic ulcer disease, gastroesophageal reflux disease in adults and children, risk reduction of NSAIDs-associated gastric ulcer, H. pylori eradication and control of pathological hypersecretory conditions associated with Zollinger-ellison syndrome [5]. However, EMT is susceptible to degradation and transformation in acid media, but it has acceptable stability under alkaline conditions [6, 7]. Hence, the exposure of esomeprazole magnesium trihydrate to the acidic contents of the stomach leads to significant degradation of the drug and results in reduced bioavailability. Thus, EMT should be protected during its passage through the acidic environment of the stomach.

Traditionally pharmaceutical formulations are developed by changing one variable at a time approach. The method is timeconsuming, requires lot of efforts and combined effects of dependent variables can't be determined [8]. The Design of Experiments (DoE) is a software-guided experimental design approach for studying the influence of several factors simultaneously. DoE provides information on the interaction of factors with a limited set of experiments. In addition, DoE fits the response data to mathematical equations, and these equations serve as models to predict responses at desired parameter (factor) values. This approach is particularly relevant for identifying the parameter space relevant for a product with specific features [9]. DoE helps in deriving maximum information from a minimal number of experiments. A variety of statistical design algorithms, such as factorial designs and BoxBehnken designs, can be employed for DoE [10].

A gastro-resistant enteric coating is a barrier applied to oral medication that prevents the release of the drug before it reaches the small intestine [11]. Most gastro-resistant coatings work by presenting a surface that is stable to highly acidic $\mathrm{pH}$ of the stomach, but breaks down rapidly at a less acidic (relatively more basic) pH. HPMCAS and HPMCP (Hypromellose phthalate) are widely used polymers [11, 12] HPMCAS is available in several grades, according to the $\mathrm{pH}$ at which the polymer dissolves and its predominant particle size. MF grade of HPMCAS dissolves above $\mathrm{pH}$ 6. HPMCP is available in several grades, according to the $\mathrm{pH}$ at which the polymer dissolves (HP 50 and HP 55 which dissolves above pH 5.0 and 5.5 respectively).

Currently, micro-particulate (Nexium) formulation of EMT is available in the market and it is costly. The microparticles in these 
formulations are basically multiple layered systems. They have an innermost base of sugar sphere which is coated with drug layer, above which there is seal coating layer and the enteric coating layer. At the end it makes the process complicated and costly due to a large number of polymers and other excipients involved.

The aim of the present investigation, therefore, was to prepare and optimise gastro-resistant microspheres of EMT using "non-aqueous solvent evaporation" or "O/O emulsion solvent evaporation" technique to retard its degradation in acidic medium of the stomach using HPMCAS as enteric coating polymer. Microparticles are spheres with size ranged between 1-1000 $\mu \mathrm{m}$.

These microparticles lack an intermediate seal coating layer and still can maintain the drug's stability both during storage and during the passage through the stomach. Thus, the formulation will be simple to manufacture and cost can be reduced. This would result in an increase in bioavailability via enhanced intestinal absorption of EMT.

\section{MATERIALS AND METHODS}

\section{Materials}

EMT was received as a gift sample from Cadila Healthcare Ltd., India. HPMCAS and HPMCP HP-55 were received as gift sample from Arihant Trading Co., India. Methanol, acetone, and potassium dihydrogen phosphate was purchased from Spectrochem Pvt. Ltd., (India), sodium hydroxide, liquid paraffin colourless heavy, and petroleum ether from Loba Chemie Pvt. Ltd., (India), concentrated $\mathrm{HCl}$ and sodium from Bicarbonate Allied Chem.

Corporation, (India), sodium sulphate and sodium phosphate from Suvidhinath Laboratories, (India), disodium hydrogen phosphate and span-80 from SD Fine-Chem Ltd., (India).

\section{Methods \\ Compatibility study by FTIR}

Compatibility of EMT with excipients (HPMCAS and HPMCP HP-55) was investigated by FTIR (Shimadzu, Japan).

\section{Preparation of EMT loaded microspheres}

"Non-aqueous solvent evaporation" or " $\mathrm{O} / \mathrm{O}$ emulsion solvent evaporation" technique was used to formulate EMT loaded gastroresistant microspheres [13]. Firstly, the polymer was dissolved in an appropriate volume of acetone by stirring. Then the buffering agent (sodium sulfate) was dispersed in polymer solution using magnetic stirrer for $15 \mathrm{~min}$. In a separate vessel, accurately weighed the amount of drug was dispersed in a volume of acetone. The drug dispersion was gradually poured into the polymer solution. The above-prepared mixture was added dropwise to the dispersion medium consisting of liquid paraffin containing Span 80. The system was stirred using an overhead propeller agitator at appropriate rpm at $30-35{ }^{\circ} \mathrm{C}$ for a period of 3-4 $\mathrm{h}$, to ensure complete evaporation of the organic phase. The liquid paraffin was decanted, and the microspheres were separated by filtration through a filter paper, washed thrice with petroleum ether and air dried for $24 \mathrm{~h} \mathrm{[13-16].}$

Formulation optimisation of gastro resistant microspheres by $3^{3}$ factorial design

A $3^{3}$ factorial design was used to prepare different batches of gastro resistant microspheres. On the basis of preliminary trial results, 3 independent variables (EMT: HPMCAS ratio, Concentration of Span 80 and Stirring speed) were selected at 3 levels: low, high and medium and \% entrapment efficiency and particle size were taken as response variables. For optimisation by $3^{3}$ factorial design, Design expert ${ }^{\circledR}$ version 8.0.7.1 software was employed. 27 batches of different combinations were prepared by taking values of the independent variables as shown in table 1.

Table 1: Selection of independent variables in $3^{3}$ factorial design

\begin{tabular}{llll}
\hline Independent variable & Variable level & & Medium(0) \\
\cline { 2 - 4 } & Low(-1) & $6: 1$ & $8: 1$ \\
\hline EMT: HPMCAS ratio $\left(\mathrm{X}_{1}\right)$ & $4: 1$ & 1.0 & 1.5 \\
Concentration of Span $80(\mathrm{X} 2)(\%)$ & 0.5 & 1000 & 1300 \\
Stirring speed $\left(\mathrm{X}_{3}\right)(\mathrm{rpm})$ & 700 & & \\
\hline
\end{tabular}

\section{Statistical data analysis}

Various RSM (Response surface methodology) computations for the current optimisation study were performed employing Design expert ${ }^{\circledR}$ software (version 8.0.7.1), State ease Inc., USA [17].

Polynomial models including interaction and quadratic terms were generated for all the response variables using multiple linear regression analysis (MLRA) approaches. The general form of the MLRA model is represented in below.

$$
\begin{gathered}
Y_{i}=b_{0+} b_{1} X_{1}+b_{2} X_{2}+b_{3} X_{3}+b_{12} X_{1} X_{2+} b_{13} X_{1} X_{3+} b_{23} X_{2} \\
X_{3}+b_{11} X_{1}{ }^{2}+b_{22} X_{2}{ }^{2}+b_{33} X_{3}{ }^{2}
\end{gathered}
$$

Where, $b_{0}$ is the intercept representing the arithmetic mean response of 27 runs,

$b_{1}$ to $b_{33}$ are the regression coefficients,
$\mathrm{Y}$ is the dependent variable,

$\mathrm{X}_{1}, \mathrm{X}_{2}$ and $\mathrm{X}_{3}$ are the independent variables.

The statistical validity of the polynomials was established on the basis of ANOVA provision in the design expert software. Subsequently, feasibility and grid searches were performed to locate the composition of optimum formulations. Also 3-D response surface graphs and 2-D contour plots were constructed using the design expert software [17].

\section{Data optimisation and model validation}

Three optimum checkpoint batches were prepared (table 2) and evaluated for various response properties. Subsequently, the resultant experimental data of response properties were quantitatively compared with that of the predicted values with the help of t-test [17].

\begin{tabular}{|c|c|c|c|}
\hline \multirow[t]{2}{*}{ Ingredients } & \multicolumn{3}{|c|}{ Formulation batch code } \\
\hline & CP1 & CP2 & CP3 \\
\hline EMT (mg) & 100 & 100 & 100 \\
\hline HPMCAS (mg) & 460 & 640 & 760 \\
\hline Sodium sulfate (mg) & 20 & 20 & 20 \\
\hline Acetone (ml) & 20 & 20 & 20 \\
\hline Liquid Paraffin (ml) & 60 & 60 & 60 \\
\hline Span $80(\% \mathrm{~V} / \mathrm{V})$ & 0.63 & 0.9 & 1.21 \\
\hline Stirring Speed (rpm) & 725 & 985 & 1198 \\
\hline
\end{tabular}

Table 2: Checkpoint batch formulation

*EMT: Esomeprazole magnesiu trihydrate, HPMCAS: Hypromellose acetate succinate. 
Numerical optimisation method was employed using desirability function in software to optimise the formulation with desired responses. Constraints set for the formulation of enteric coated microspheres were: $\mathrm{X}_{1}$-EMT: HPMCAS ratio and $\mathrm{X}_{2}$-Concentration of Span 80-in range while $\mathrm{X}_{3}$-Stirring speed was kept at maximum, which would give desired response values, i.e., minimum particle size ( $\mathrm{YPS}_{\mathrm{PS}}$ and maximum entrapment efficiency $\left(\mathrm{Y}_{\mathrm{EE}}\right)$. The experiment was carried out using levels obtained from numerical optimisation from software and desirability plot was generated using design expert.

\section{Percentage yield}

Percentage yield of each batch was calculated using the expression.

$$
\% \text { Yield }=\frac{\text { Weight of microspheres }}{\text { Weight of solid starting material }} * 100
$$

\section{Particle size and size distribution}

The particle size of prepared microspheres was measured using master size (Mastersizer 2000 ver. 5.1, Malvern Instruments Ltd., Malvern, UK). The dispersant used was $0.1 \mathrm{~N} \mathrm{HCl}$ and the average particle size was calculated in microns $[18,19]$.

\section{Micromeritic properties}

The microspheres were characterised for different flow properties such as angle of repose, carr's index and hausner's ratio [20,21].

\section{Scanning electron microscopy (SEM)}

Surface morphology of microspheres was studied under a scanning electron microscope (JEOL, JSM 5760 LY). Samples were mounted on stubs and coated for 120 seconds with a layer of gold using a sputter coater (polaron SC 502). SEM photographs were taken at room temperature $\left(25^{\circ} \mathrm{C}\right)$ using a low beam voltage of $20 \mathrm{kV}$ [22].

\section{Differential scanning calorimetry (DSC)}

The DSC thermograms of plain drug (EMT), plain polymer (HPMCAS) and prepared microspheres were taken on a differential scanning calorimeter (Shimadzu DSC-60) between 40 and $250{ }^{\circ} \mathrm{C}$ at a heating rate of $10^{\circ} \mathrm{C} / \mathrm{min}$ with nitrogen supplied at $30 \mathrm{ml} / \mathrm{min}$ [22].

\section{Drug entrapment efficiency}

The microspheres were crushed in a glass mortar and dissolved in $10 \mathrm{ml}$ of methanol. The solution was filtered and was analysed for drug content using UV spectrophotometer (Shimadzu 1700, Japan) at $302 \mathrm{~nm}[23,24]$. The drug entrapment efficiency was calculated by the following formula:

$\%$ Entrapment efficiency

$$
\begin{aligned}
& =\frac{\text { amt. of drug present in the formulation }}{\text { amt. of drug taken in the formulation }} \\
& * 100
\end{aligned}
$$

\section{In vitro drug release}

The in vitro dissolution studies for all the formulations were carried out in two steps, using USP apparatus type-I (basket) at $100 \mathrm{rpm}$. The dissolution medium consisted of $0.1 \mathrm{~N} \mathrm{HCl}$ for first $2 \mathrm{~h}$ followed by phosphate buffer $\mathrm{pH} 6.8$, maintained at $37^{\circ} \mathrm{C} \pm 0.5{ }^{\circ} \mathrm{C}$. The drug release at different time intervals (Acid stage: $120 \mathrm{~min}$; Buffer stage: $10,20,30,45$ and $60 \mathrm{~min}$ ) was measured by UV-spectrophotometer (Shimadzu 1700, Japan) at $302 \mathrm{~nm}$ [15].

\section{In vivo anti-ulcer activity}

In vivo anti-ulcer activity was carried out using male wistar rats (180-220 g) and protocol [No. MSU/IAEC/2011/22] was approved by the Institutional Animal Ethics Committee (IAEC) of M. S. University of Baroda, Vadodara, India. The study was carried out in accordance with the CPCSEA guidelines, Department of animal welfare, Government of India. Each group was housed in cages placed in an animal room with a constant temperature of $22^{\circ} \mathrm{C}$ and a fixed 12-hour light-dark cycle with free access to water. Animals were randomly divided into 3 groups (table 3), each containing 4 rats. They were fasted overnight, and ulcer was induced by oral administration of absolute alcohol ( $5 \mathrm{ml} / \mathrm{kg}$ ) [25]. Formulations $(20$ $\mathrm{mg} / \mathrm{kg}$ of drug) were administered orally with the help of cannula 1 $h$ before the administration of ethanol. Rats were sacrificed by an overdose of anaesthesia after $2 \mathrm{~h}$ of ethanol administration; their stomachs were removed, opened along the greater curvature, and examined for lesion measurements.

Table 3: Groups of rats for the in vivo antiulcer activity

\begin{tabular}{ll}
\hline Group & Administered samples \\
\hline Control 1 & $42 \%$ sodium bicarbonate solution \\
Control 2 & EMT solution $(2 \mathrm{mg} / \mathrm{ml}, 20 \mathrm{mg} / \mathrm{kg})$ \\
Treatment & Microspheres dispersion (equivalent to $2 \mathrm{mg}$ of EMT) \\
\hline
\end{tabular}

Ulcer indices (UI) were calculated using the equation:

$$
\mathrm{UI}=\frac{10}{\mathrm{x}}
$$

Where $\mathrm{x}$ is the total mucosal area divided by the total ulcerated area.

\section{RESULTS AND DISCUSSION}

\section{Compatibility study of EMT with excipients by FTIR}

Compatibility study between polymer and drug was carried out using infrared analysis (fig. 1). The spectra of pure EMT showed its characteristic bands (A). The bands observed in the spectrum of a mixture of EMT+HPMCAS did not show any shift (B) suggesting their compatibility. The bands observed in the spectrum of a mixture of EMT+HPMCP HP-55 (C) showed a shift of carboxylate peak from 1614 to $1724 \mathrm{~cm}^{-1}$ suggesting that a new chemical bond was formed, indicating an incompatibility between HPMCP HP-55 and EMT.

Hence, HPMCAS was chosen as the polymer for preparing the gastroresistant microspheres.

\section{Optimisation using $3^{\mathbf{3}}$ factorial design}

Surfactant concentration, drug: polymer ratio and stirring speed were taken as independent variables and their effects on responses such as particle size and entrapment efficiency were optimised using $3^{3}$ factorial design.
Full model equations for entrapment efficiency (EE) and particle size (PS) were established using the Design expert as given below.

$\mathrm{Y}_{\mathrm{EE}}=50.50+2.13 \mathrm{X}_{1}+3.67 \mathrm{X}_{2}-6.94 \mathrm{X}_{3}+0.045 \mathrm{X}_{1} \mathrm{X}_{2}-0.26 \mathrm{X}_{1} \mathrm{X}_{3}+0.56 \mathrm{X}_{2}$ $\mathrm{X}_{3}+0.023 \mathrm{X}_{1}^{2}+0.62 \mathrm{X}_{2}^{2}+1.28 \mathrm{X}_{3}^{2}$.

$\mathrm{Y}_{\mathrm{PS}}=281.20+7.24 \mathrm{X}_{1}-8.51 \mathrm{X}_{2}-133.30 \mathrm{X}_{3}-0.021 \mathrm{X}_{1} \mathrm{X}_{2}+0.66 \mathrm{X}_{1} \mathrm{X}_{3}+1.83 \mathrm{X}_{2}$ $\mathrm{X}_{3}+0.39 * \mathrm{X}_{1}^{2}-23.81 \mathrm{X}_{2}{ }^{2}+33.59 \mathrm{X}_{3}^{2}$

The terms having coefficients with $p>0.05$ are least contributing in the prediction of response $[22,26]$. Thus, neglecting non-significant $(p>0.05)$ terms from the full model and applying regression between significant terms, equations of reduced model were obtained [Equations (3) and (4)].

$\mathrm{Y}_{\mathrm{EE}}=50.50+2.13 \mathrm{X}_{1}+3.67 \mathrm{X}_{2}-6.94 \quad \mathrm{X}_{3}-0.26 \quad \mathrm{X}_{1} \mathrm{X}_{3}+0.56 \quad \mathrm{X}_{2} \mathrm{X}_{3}+0.62 \mathrm{X}_{2}{ }^{2}$ $+1.28 \mathrm{X}_{3}^{2} \ldots \ldots .(3)$

$\mathrm{Y}_{\mathrm{PS}}=281.20+7.24 \mathrm{X}_{1}-8.51 \mathrm{X}_{2}-133.30 \mathrm{X}_{3}+1.83 \mathrm{X}_{2} \mathrm{X}_{3}-23.81 \mathrm{X}_{2}{ }^{2}+33.59 \mathrm{X}_{3}{ }^{2}$ ..........(4)

\section{(a) Effect on \% entrapment efficiency}

From sthe multiple regression equation (3), it was observed that $X_{1}$, $\mathrm{X}_{2}, \mathrm{X}_{3}, \mathrm{X}_{1} \mathrm{X}_{3}, \mathrm{X}_{2} \mathrm{X}_{3}, \mathrm{X}_{2}{ }^{2}$ and $\mathrm{X}_{3}{ }^{2}$ had significant effect on EE. Positive values of drug: polymer ratio $\left(\mathrm{X}_{1}\right)$ and concentration of Span $80\left(\mathrm{X}_{2}\right)$ indicated the agonistic effect on EE, i.e. an increase in $\mathrm{X}_{1}$ or $\mathrm{X}_{2}$ 
increased the value of EE. As the ratio of drug-to-polymer increased, encapsulation efficiency increased. An increase in polymer concentration resulted in the formation of larger microspheres entrapping greater amounts of the drug, resulting in higher encapsulation efficiency [27].

Moreover, as the concentration of Span 80 increases, the stability of formed globules also increases which will cause an increase in drug loading $[28,29]$. Negative value of stirring speed $\left(X_{3}\right)$ indicated its antagonistic effect on EE, i.e. an increase in stirring speed reduced the value of EE.
The relationship between the dependent and independent variables was elucidated by constructing contour plots and response surface analysis. These types of plots are useful in the study of the effects of two factors on the response at one time.

The interaction term AC had a significant effect on \% entrapment efficiency $\left(\mathrm{Y}_{1}\right)$ as it can be seen by p-value (0.0063). Hence, contour plot and 3D surface plot (fig. 2) were plotted to check the effect of EMT: HPMCAS $\left(\mathrm{X}_{1}\right)$ and stirring speed $\left(\mathrm{X}_{3}\right)$ at fixed value of $\mathrm{X}_{2}$ on \% entrapment efficiency $\left(\mathrm{Y}_{1}\right)$. The plots were found to be non-linear; therefore non-linear relationship existed between $\mathrm{X}_{1}$ and $\mathrm{X}_{3}$ variables.
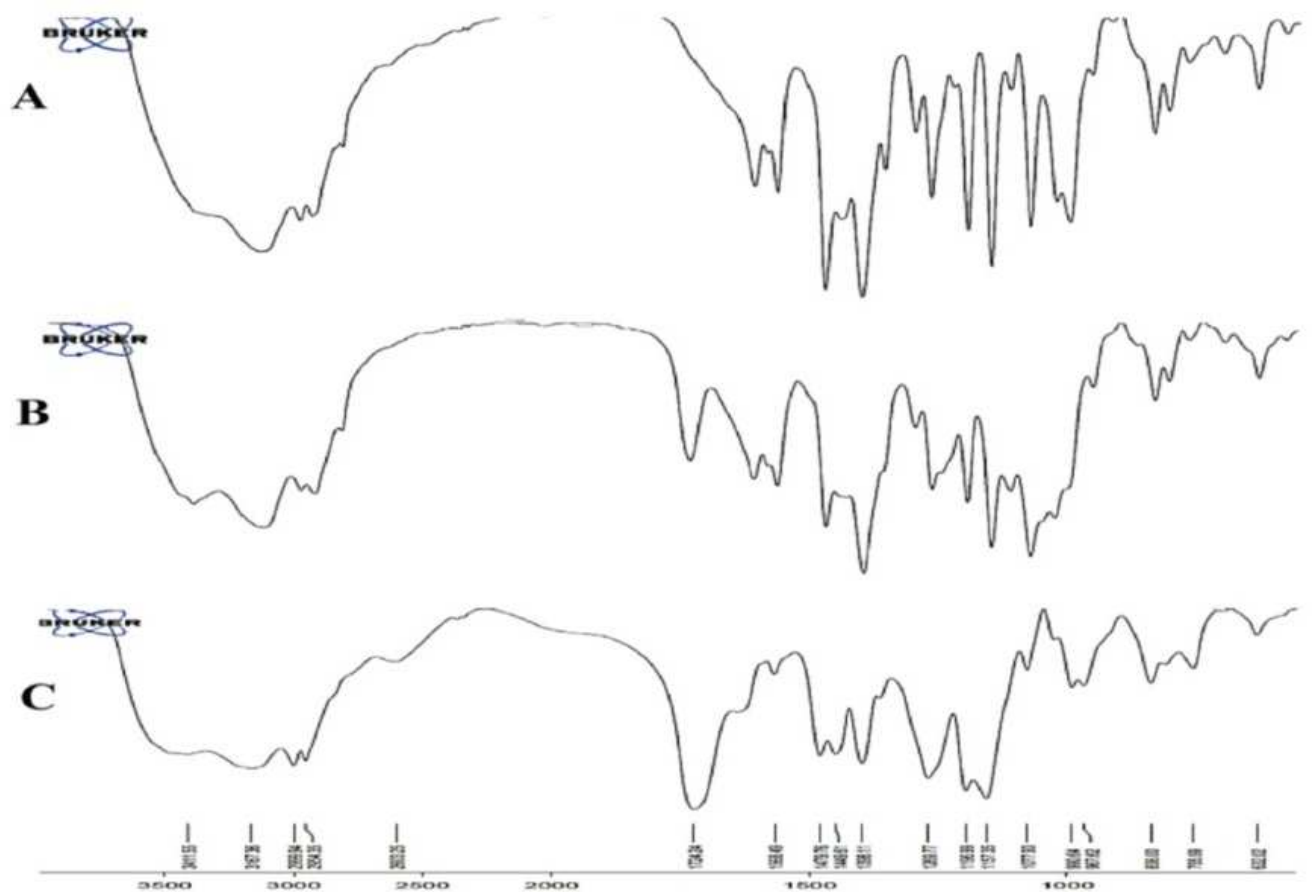

Fig. 1: Infrared spectra of A. pure EMT B. mixture of EMT+HPMCAS C. mixture of EMT+HPMCP HP-55

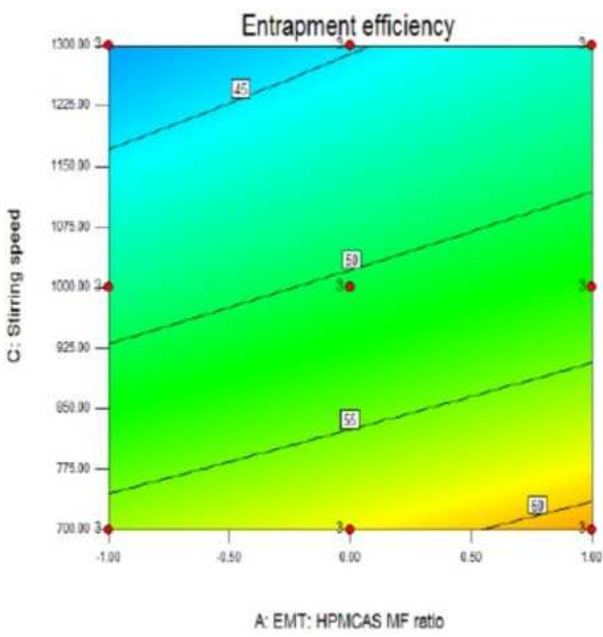

(A)

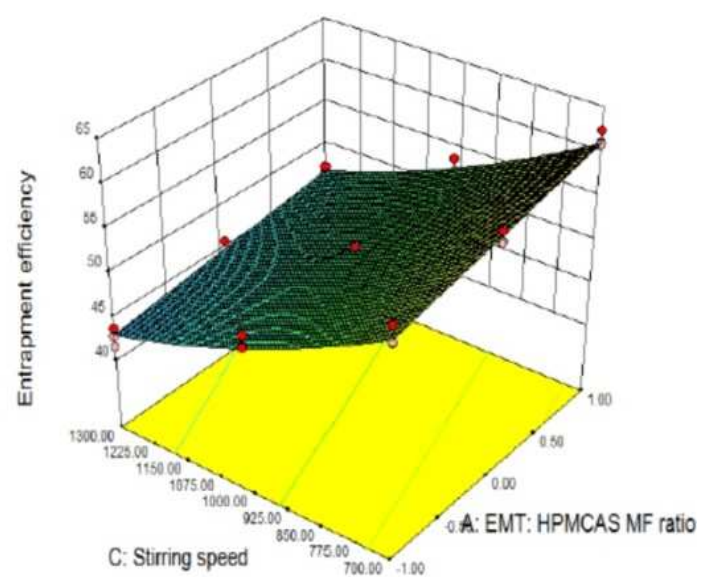

(B)

Fig. 2: (A) Contour Plot and (B) 3D plot showing effect of HPMCAS: EMT ratio and stirring speed on \% entrapment efficiency

The interaction term $\mathrm{BC}$ had a significant effect on \% entrapment efficiency $\left(\mathrm{Y}_{1}\right)$ as it can be seen by p-value $(<0.0001)$. Contour plot and 3D surface plot (fig. 3) were plotted to check the effect of concentration of Span $80\left(\mathrm{X}_{2}\right)$ and stirring speed $\left(\mathrm{X}_{3}\right)$ at a constant value of $\mathrm{X}_{1}$ on \% entrapment efficiency $\left(\mathrm{Y}_{1}\right)$. The plots were found to be non-linear; therefore non-linear relationship existed between $\mathrm{X}_{2}$ and $\mathrm{X}_{3}$ variables. 


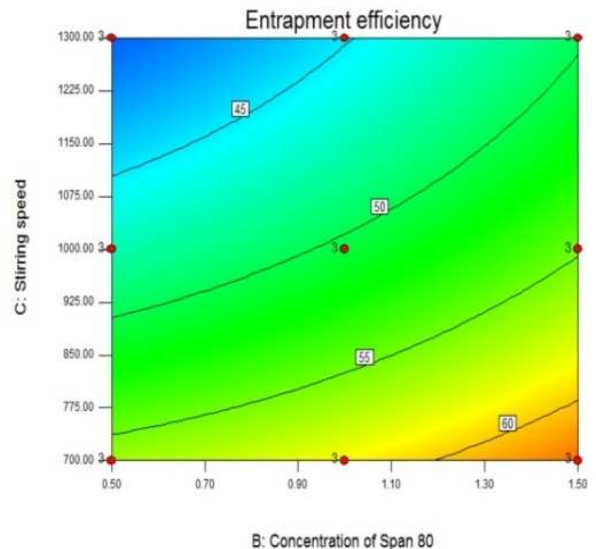

(A)

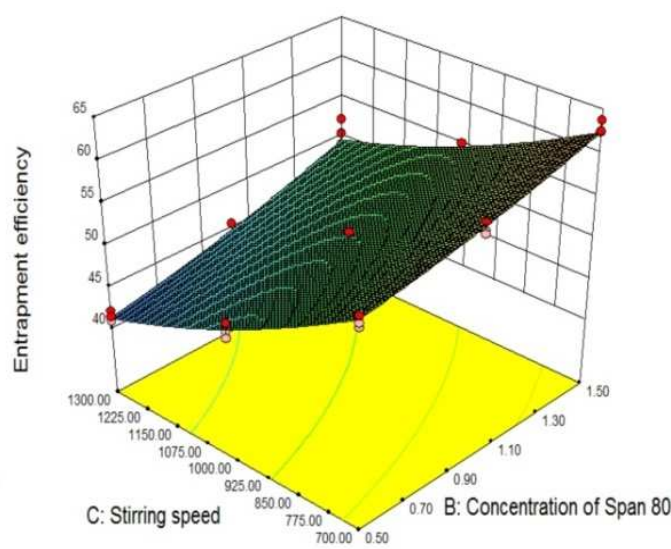

(B)

Fig. 3: (A) Contour Plot and (B) 3D plot showing effect of concentration of span 80 and stirring speed on \% entrapment efficiency

The model F-value of 40.01 implied that the model was significant $(\mathrm{p}<0.0001)$. The value of $\mathrm{R}^{2}$ for polynomial equation was found to be 0.9942 (table 4). "Adeq precision" measures the signal to noise ratio. The ratio of 125.791 indicated an adequate signal. Therefore, this model can be used to navigate the design space.

Table 4: Summary of results of regression analysis for responses $Y_{1}$ and $Y_{2}$

\begin{tabular}{|c|c|c|c|c|c|c|}
\hline Response & $\mathbf{R}^{2}$ & Adjusted $\mathrm{R}^{2}$ & Predicted $\mathrm{R}^{2}$ & SD & $\% \mathrm{CV}$ & Mean \\
\hline $\mathrm{Y}_{1}(\% \mathrm{EE})$ & 0.9942 & 0.9935 & 0.9922 & 0.55 & 1.06 & 51.78 \\
\hline $\mathrm{Y}_{2}$ (PS) & 0.9997 & 0.9997 & 0.9996 & 2.06 & 0.71 & 287.98 \\
\hline
\end{tabular}

\section{(b) Effect on particle size}

From the multiple regression equations (4), it was observed that $X_{1}, X_{2}$, $\mathrm{X}_{3}, \mathrm{X}_{2} \mathrm{X}_{3}, \mathrm{X}_{2}{ }^{2}$ and $\mathrm{X}_{3}{ }^{2}$ had significant effect on PS. Positive values of drug: polymer ratio $\left(\mathrm{X}_{1}\right)$ in Eq 4 implied an agonistic effect on PS, i.e. an increase in $\mathrm{X}_{1}$ increased the value of PS. Increasing polymer concentration produced a significant increase in the viscosity, thus leading to an increase of emulsion droplet size and finally a larger microsphere size [27]. When the dispersed phase with higher viscosity was poured into the continuous phase (external phase), higher viscosity of the internal phase making the coalescence of emulsified droplet easier $[30,31]$. Negative values of concentration of span $80\left(\mathrm{X}_{2}\right)$ and stirring apeed $\left(\mathrm{X}_{3}\right)$ indicated their antagonistic effect on PS, i.e. an increase in the concentration of span 80 or stirring speed reduced the PS. This might be due to the stabilisation of the oil droplets with Span 80 . Stirring speed is an important parameter for controlling the dispersion's droplet size in the continuous phase. It was observed that increase in the stirring speed is reduced particle size which might be due to stronger shear stress and higher turbulence that was generated at higher speed creating smaller emulsion droplets which resulted in the formation of smaller particles $[32,33]$.

The interaction term $\mathrm{X}_{2} \mathrm{X}_{3}$ had a significant effect on particle size $\left(\mathrm{Y}_{2}\right)$ as it can be seen by p-value $(<0.0001)$. Contour plot and 3D surface plot (fig. 4) were plotted to check the effect of concentration of span $80\left(\mathrm{X}_{2}\right)$ and stirring speed $\left(\mathrm{X}_{3}\right)$ on particle size $\left(\mathrm{Y}_{2}\right)$ at a constant value of $X_{1}$. The plots were found to be non-linear; therefore nonlinear relationship exists between $\mathrm{X}_{2}$ and $\mathrm{X}_{3}$ variables.

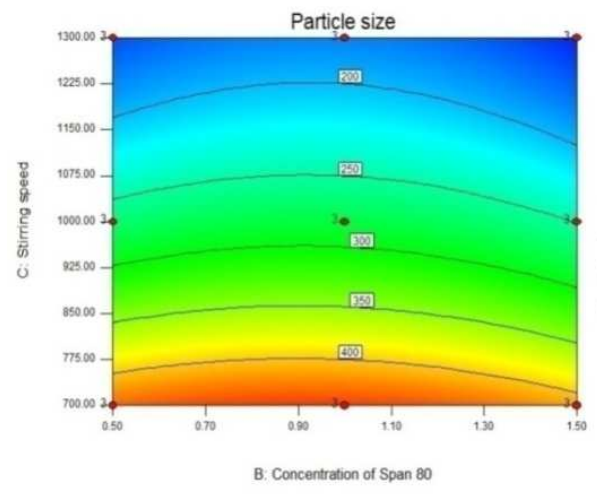

(A)

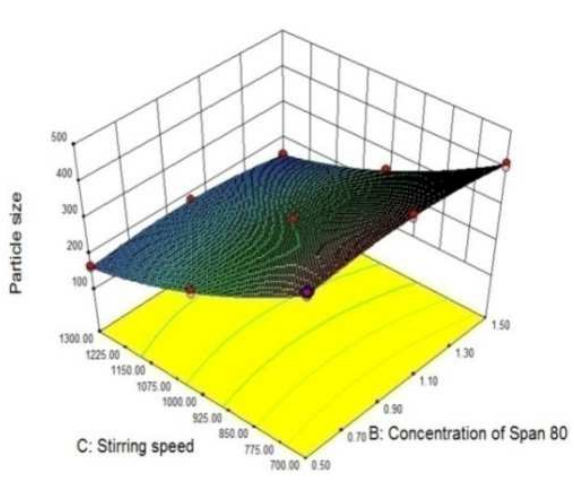

(B)

Fig. 4: (A) Contour plot and (B) 3D plot showing effect of concentration of span 80 and stirring speed on particle size

The model F-value of 240.27 implied that the model was significant $(\mathrm{p}<0.0001)$. The value of $\mathrm{R}^{2}$ for polynomial equation was found to be
0.9997 (table 4). The ratio of 408.671 indicated an adequate signal. Therefore, this model can be used to navigate the design space. 


\section{Validation of model (Check Point Analysis)}

A checkpoint analysis was performed to validate the equation that described the influence of the factors on \% entrapment efficiency and particle size. Results for predicted and observed values of dependent parameters are shown in table 5.
When both experimentally obtained and theoretically computed EE ( $p$-value $=0.83$ ) and PS ( $p$-value $=0.76)$ values were compared using student t-test, the difference was found to be non-significant $(p>0.05)$ in both cases.

Thus the proposed model can be used to navigate the design space [34].

Table 5: Checkpoint batches

\begin{tabular}{llll}
\hline Checkpoint batch & \multicolumn{2}{c}{ \% Entrapment efficiency* } & Particle size $(\boldsymbol{\mu m})^{*}$ \\
\cline { 2 - 4 } & Predicted & Observed & Predicted \\
\hline CP1 & 56.28 & $55.19 \pm 2.31$ & 427.02 \\
CP2 & 51.18 & $52.03 \pm 1.87$ & 288.99 \\
CP3 & 48.05 & $48.72 \pm 3.01$ & 214.14 \\
\hline
\end{tabular}

* Data are expressed mean \pm standard deviation $(\mathrm{SD}, \mathrm{N}=3$ )

\section{Optimisation using desirability function}

Desirability is an objective function that ranges from zero (outside of limits) and one (at the goal).
The contour plots and 3D surface plots showing desirability of the optimised batch to achieve minimum PS and maximum EE are shown in fig. $5 \mathrm{~A}$ and $5 \mathrm{~B}$.

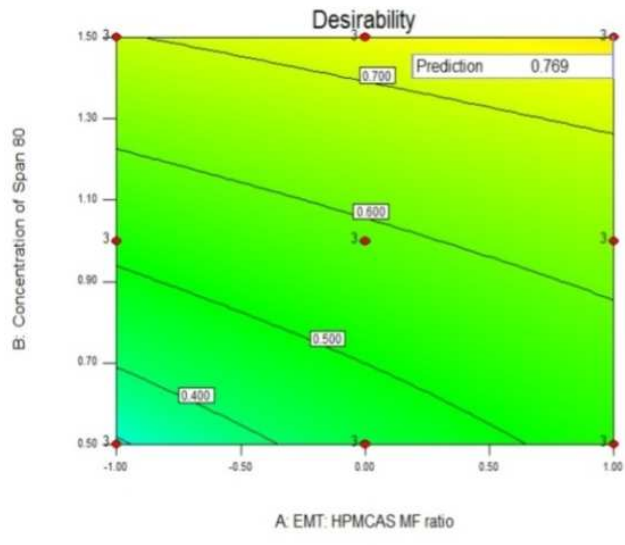

(A)

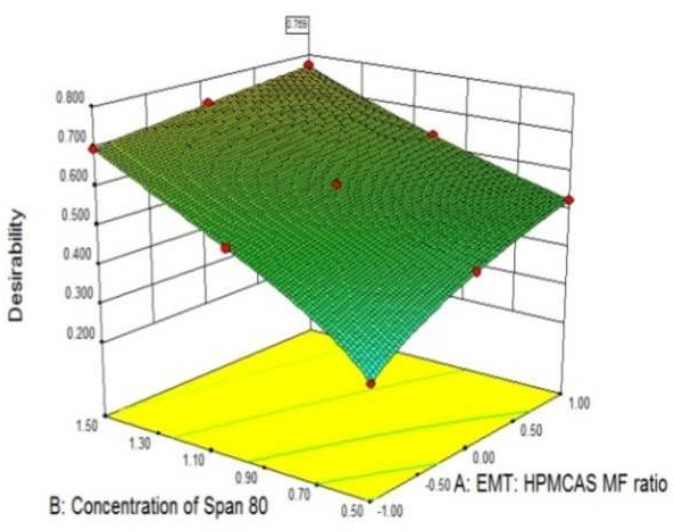

(B)

Fig. 5: (A) Contour plot and (B) 3D surface plot showing desirability of optimised batch

Fig. 5C shows the ramp display of parameters for interpretation of optimum solution parameters. A dot on each ramp reflects the factor setting or response prediction for that solution. The height of the dot shows the desirability of the process [35]. From
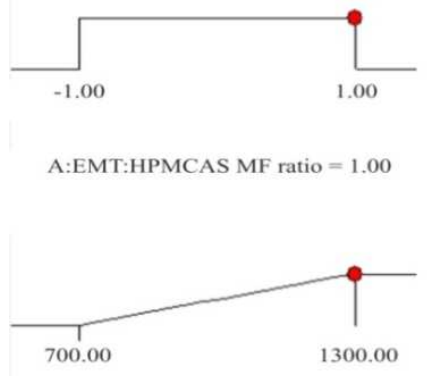

C: Stirring Speed $=1300.00$

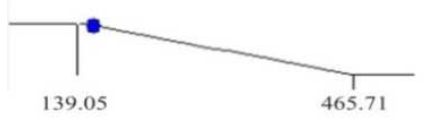

Particle Size $=159.287$

( C ) the graph, the maximum desirability of 0.769 indicated that optimum formulation was achieved at 1:8 drug:polymer ratio, $1.5 \% \mathrm{w} / \mathrm{w}$ concentration of Span 80 and a stirring speed of 1300 rpm.

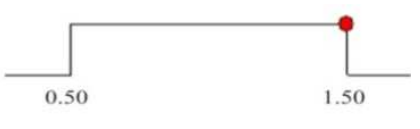

B:Concentration of Span $80=1.50$

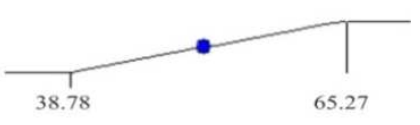

Entrapment efficiency $=51.6272$

Desirability $=0.769$

Fig. 5: (C) Ramp graph showing desirability of optimized batch 
Bar graph represents individual desirability of all responses in correspondence with combined desirability. Bar Graph (fig. 5D) showed that for individual factors desirability of 1 , PS desirability 0.9380 and EE desirability 0.4049 with combined desirability of 0.7691 were obtained.

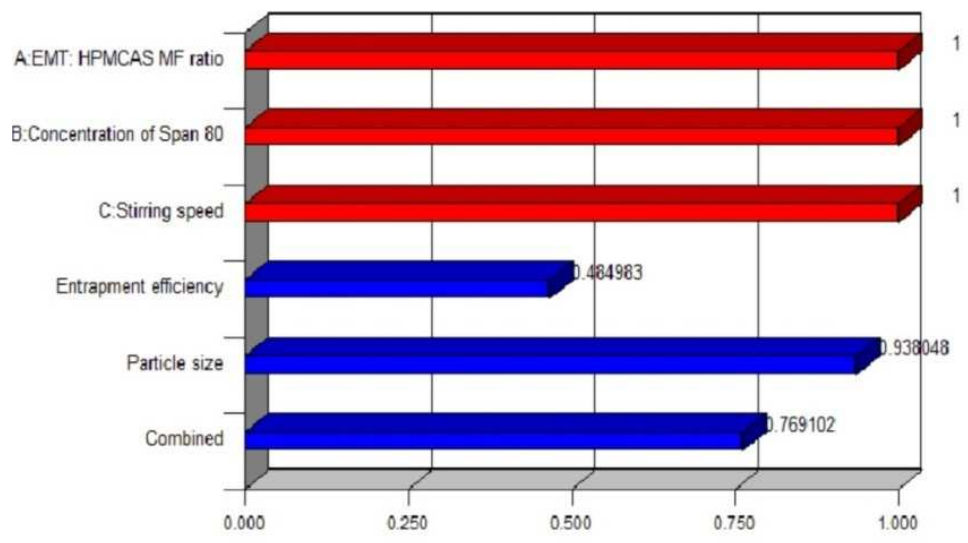

(D)

Fig. 5: (D) Bar graph showing desirability of optimised batch

The results obtained for the optimised batch $(49.63 \pm 1.23 \%$, $170.12 \pm 3.36 \mu \mathrm{m})$ were very close to that given by the software $(51.62 \%$ and $159.28 \mu \mathrm{m})$. Thus, it was concluded that batch GM-26 may be considered as the optimized batch.

\section{Micromeritic properties}

The values of angle of repose, carr's index and the hausner ratio of the optimized batch (table 6) were found to be $28.66^{\circ} \pm 0.20$, $13.10 \pm 0.43$ and $1.15 \pm 0.33$ respectively, indicating good flow characteristics of the microspheres suitable for handling and filling into capsule [26].

\section{Differential scanning calorimetry (DSC)}

DSC analyses were carried out for EMT, HPMCAS MF and microspheres (fig. 6). Thermogram of EMT showed a sharp exothermic peak at $198{ }^{\circ} \mathrm{C}$ indicating its melting point. The thermogram for microspheres showed no event for EMT. The lowering of crystallinity of polymer was indicated by shifting of polymer peak towards lower temperature $\left(282{ }^{\circ} \mathrm{C}\right.$ to $\left.264^{\circ} \mathrm{C}\right)$. The results suggested that EMT loaded HPMCAS microspheres were composed of a homogeneous phase, in which the polymer presented a lower degree of crystallinity than the raw material and the drug was molecularly dispersed in the polymer $[19,36]$.

Table 6: Evaluation of optimised batch

\begin{tabular}{llll}
\hline \% Entrapment efficiency* & Particle size* $(\boldsymbol{\mu m})$ & Angle of repose* $\left.^{*}{ }^{\circ}\right)$ & Carr's index $^{*}$ \\
\hline $49.63 \pm 1.23$ & $170.12 \pm 3.36$ & $28.66 \pm 0.20$ & $13.70 \pm 0.43$ \\
\hline
\end{tabular}

* Data are expressed mean \pm standard deviation $(\mathrm{SD}, \mathrm{N}=3$ )
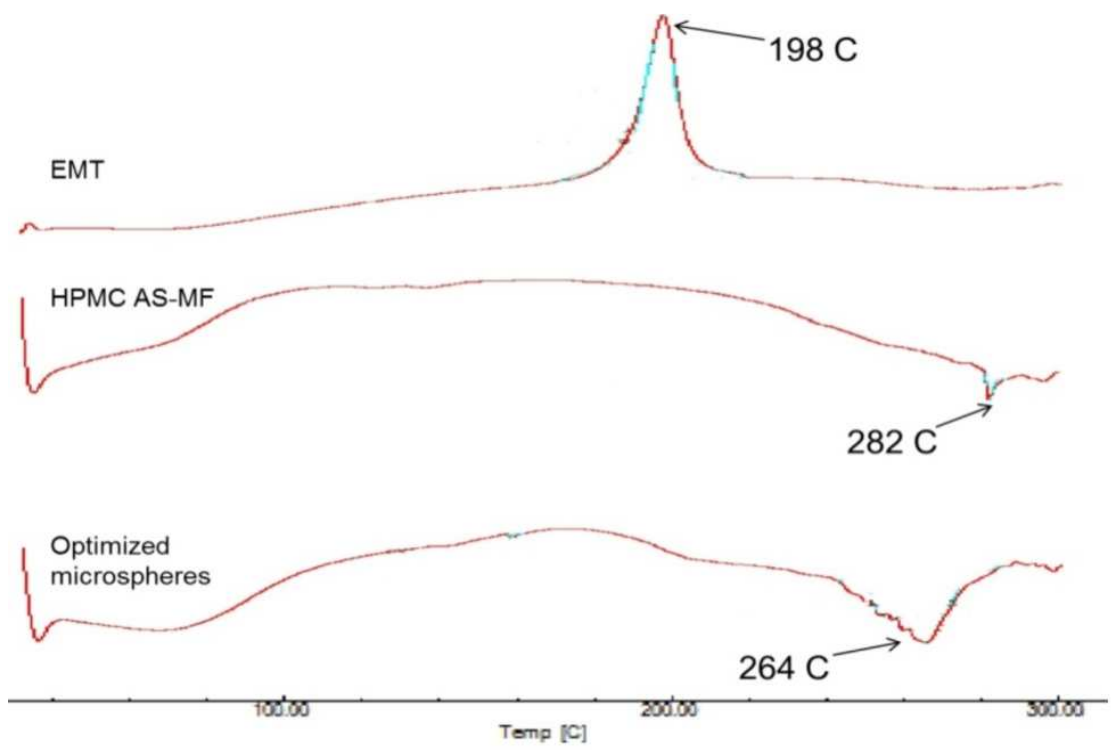

Fig. 6: DSC thermogram of EMT, HPMCAS and microspheres of optimised batch 


\section{Scanning electron microscopy (SEM)}

Results of Scanning electron microscopy demonstrated the spherical nature of microspheres as shown in fig. 7. The surface of microspheres was smooth and nonporous. When combined with DSC results, it may be implied that the drug was entrapped in the polymer matrix and hence would remain protected by the gastro resistant polymer.

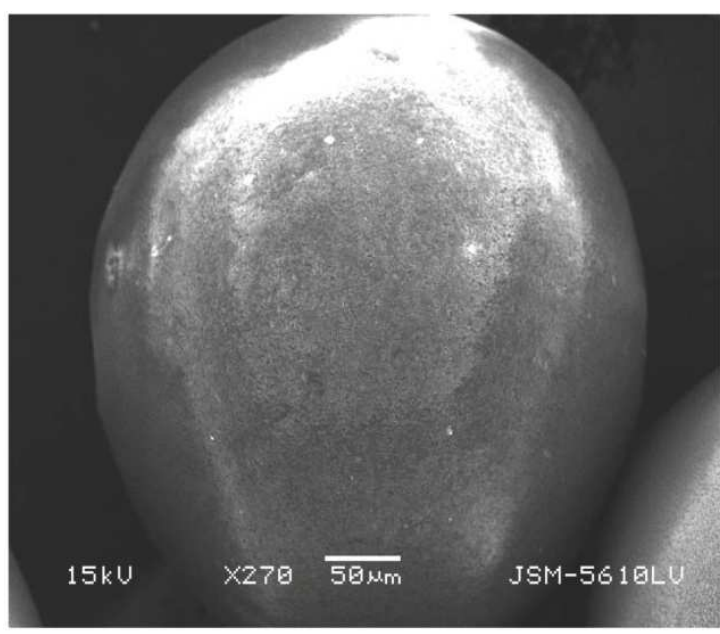

(A)

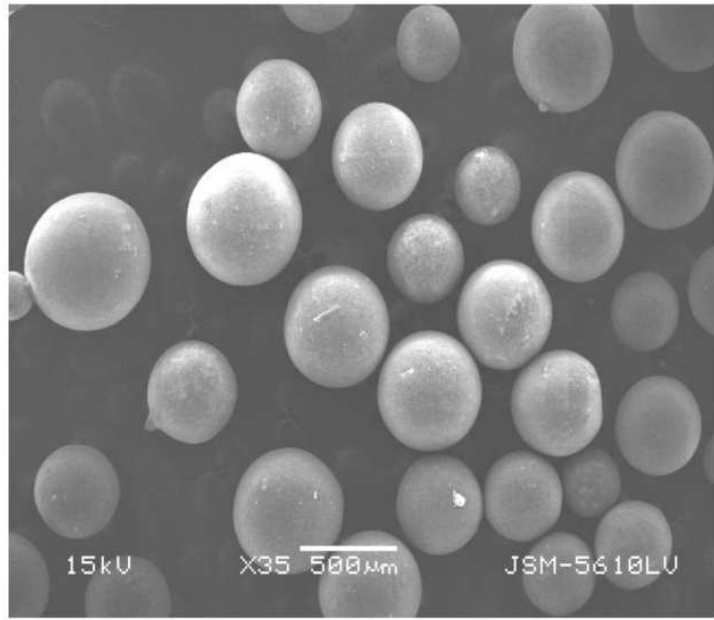

(B)

Fig. 7: SEM image showing (A) surface of microsphere (B) size of microspheres

\section{In vitro drug release}

In vitro drug release profile of optimised batch showed that only $4.28 \pm 1.23 \%$ drug was released in acidic media after $120 \mathrm{~min}$ whereas $93.46 \pm 1.20 \%$ drug was released in the basic media after 60 min (fig. 8).

As per $<711>$ USP for delayed release dosage forms, not more than $10 \%$ of the drug should be released in acidic media after $120 \mathrm{~min}$ Hence, it was proved that the prepared microspheres were gastroresistant $[37,38]$. It was concluded that the developed microspheres would prevent drug release in the acidic medium of the stomach so that intestinal absorption of the drug would be improved, leading to increased bioavailability.

To determine drug release kinetics, the in vitro release data was fitted to various kinetics models such as zero order, first order, Higuchi and korsemeyer peppas [18]. The model was selected based on correlation coefficient $\left(r^{2}\right)$ value. The data (table 7) revealed that release of drug from EMT loaded microspheres followed first order kinetics indicating that rate of drug release was concentration dependent [28].

\section{In vivo anti-ulcer activity}

Oral administration of ethanol to the control groups clearly showed hemorrhagic lesions developed in the glandular portion of the stomach due to stasis in gastric mucosa (fig. 9).

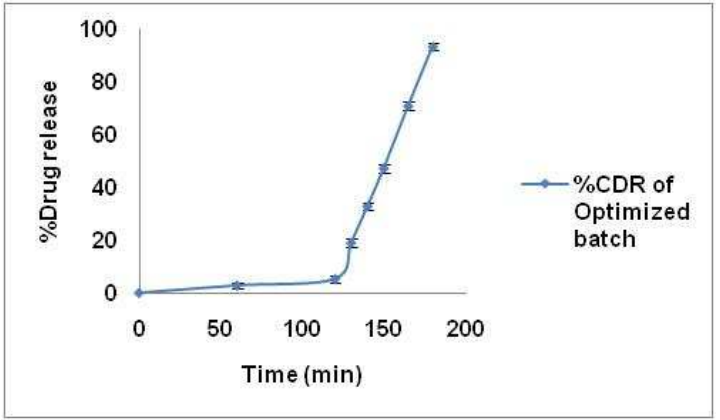

Fig. 8: In vitro drug release of optimised batch of gastroresistant microspheres (mean $\pm \mathrm{SD}, \mathrm{n}=3$ )

Table 7: Linear correlation coefficient values of various models for in vitro release study

\begin{tabular}{|c|c|c|c|}
\hline \multicolumn{4}{|c|}{ Linear correlation coefficient $\left(\mathrm{r}^{2}\right)$ values } \\
\hline Zero order & First order & Higuchi & Korsemeyer peppas \\
\hline 0.689 & 0.974 & 0.620 & 0.633 \\
\hline
\end{tabular}

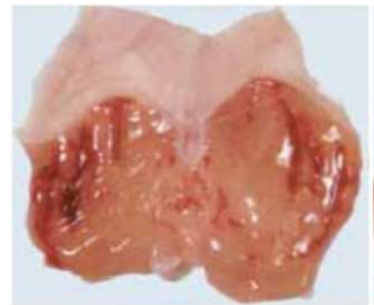

(A)

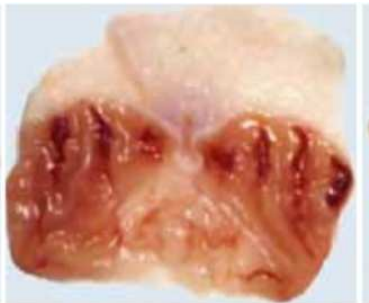

(B)

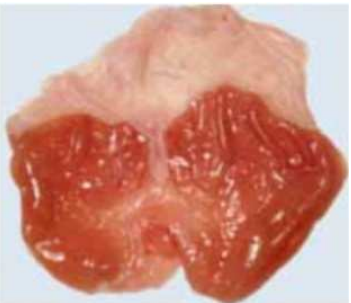

(C)

Fig. 9: Photographs of the stomachs opened along the greater curvature in ethanol-induced ulcer rat model. (A) Stomach after administration of bicarbonate solution and (B) EMT solution [both showing the hemorrhagic lesions developed in the glandular portion of the stomach] (C) microspheres aqueous dispersion [no lesions observed] 
The gastric ulcer indexes (fig. 10) were found to be $0.42 \pm 0.15$ for the sodium bicarbonate solution (Control 1), $0.46 \pm 0.17$ for EMT solution (Control 2), and $0.07 \pm 0.04$ for EMT-loaded HPMCAS microspheres (Treatment) respectively. The Kruskal-wallis test detected statistical differences $(p=0.002)$ among these indexes. The multiple analysis (Student-Newman-Keuls) showed that the
EMT-loaded HPMCAS microspheres presented a gastric ulcer index statistically lower $(\mathrm{p}<0.05)$ than those of the sodium bicarbonate solution and the EMT solution groups. Thus, the results of in vivo anti-ulcer evaluation demonstrated that microspheres were able to reduce ulcer formation caused by oral administration of ethanol significantly.

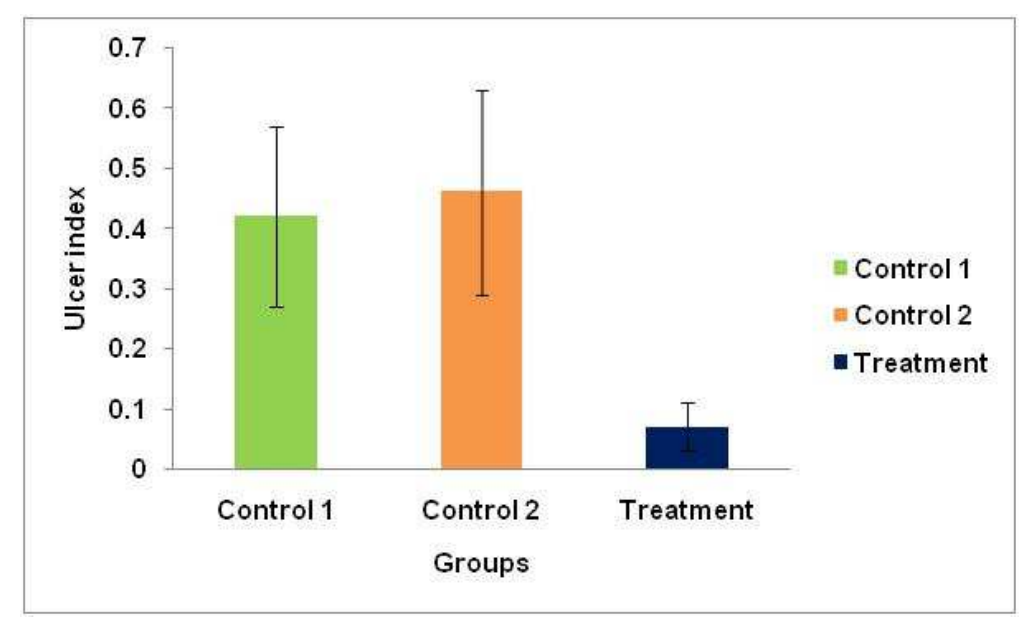

Fig. 10: Gastric ulcer indexes after administration of $42 \%$ sodium bicarbonate solution (Control 1), EMT solution (2 mg/ml) (Control 2) and EMT-loaded microspheres dispersion (Treatment) in ethanol-induced ulcer

\section{CONCLUSION}

EMT loaded microspheres were formulated using "non-aqueous solvent evaporation" or "O/O emulsion solvent evaporation" method and optimised by $3^{3}$ factorial design. DoE allowed simultaneous evaluation of EMT: HPMCAS ratio, the concentration of Span 80 and stirring speed with respect to percent entrapment efficiency and particle size. EMT loaded microspheres had good micromeritics properties. In vitro drug release data revealed that not more than $10 \%$ of the drug was released in acidic media after $2 \mathrm{~h}$ which proved that the prepared microspheres were gastro resistant. In vivo antiulcer study showed a significant reduction in ethanol-induced ulcer formation after treatment with the microspheres. The gastro resistant microspheres of EMT are thus expected to provide clinicians with a new choice of EMT formulation in the management of Peptic ulcers, GERD and Zollinger-ellison syndrome.

\section{ACKNOWLEDGEMENT}

The authors would like to thank Cadila Healthcare Ltd., India, for providing esomeprazole magnesium trihydrate as a gift sample, and to Arihant Trading Co., India, for the gift samples of HPMC acetate succinate and HPMA phthalate HP-55. The authors are grateful to the Metallurgy department, The Maharaja Sayajirao University of Baroda, Vadodara, India, for XRD and SEM studies and to the Pharmacology department, Faculty of Pharmacy for their help in the in vivo studies.

\section{CONFLICT OF INTERESTS}

The authors report no declarations of interest.

\section{REFERENCES}

1. Banker GS, Anderson NR. Tablets: the theory and practice of industrial pharmacy. India: Varghese Pub. House: 2003. p. 197-242.

2. Ling SS, Magosso E, Khan NA, Yuen KH, Barker SA. Enhanced oral bioavailability and intestinal lymphatic transport of a hydrophilic drug using liposomes. Drug Dev Ind Pharm 2006;32:335-45.

3. Vyas SP, Khar RK. Targeted and controlled drug delivery novel carrier systems. New Delhi: CBS Publishers and distributors; 2004. p. 417-52.

4. Kemala T, Budianto E, Soegiyono B. Preparation and characterization of microspheres based on a blend of poly(lactic acid) and poly(e-caprolactone) with poly(vinyl alcohol) as an emulsifier. Arabian J Chem 2012;5:103-8.

5. Dent J. Pharmacology of esomeprazole and comparisons with omeprazole. Aliment Pharmacol Ther 2003;17 Suppl 1:5-9.

6. Anroop BR. Formulation and evaluation of enteric coated tablets of proton pump inhibitor. J Basic Clin Pharm 2010;1:215-21.

7. Stroyer A, McGinity JW, Leopold CS. Solid state interactions between the proton pump inhibitor omeprazole and various enteric coating polymers. J Pharm Sci 2006;95:1342-53.

8. Gohel MC, Amin AF. Formulation optimisation of controlled release diclofenac sodium microspheres using factorial design. J Controlled Release 1998;51:115-22.

9. Yandrapu S, Kompella UB. Development of sustained-release microspheres for the delivery of SAR 1118, an LFA-1 antagonist, intended for the treatment of vascular complications of the Eye. J Ocul Pharmacol Ther 2013;29:236-48.

10. Singh B, Mehta G, Kumar R, Bhatia A, Ahuja N, Katare OP. Design, development and optimisation of nimesulide-loaded liposomal systems for topical application. Curr Drug Delivery 2005;2:143-53.

11. Khan M, Ansari VA, Kushwaha P, Kumar A, Akhtar J. Mucoadhesive microspheres for controlled delivery of drugs. Asian J Pharm Clin Res 2015;8:1-20.

12. Fang $\mathrm{Y}$, Wang G, Zhang R, Liu Z, Liu Z, Wu X, et al. Eudragit L/HPMCAS blend enteric-coated lansoprazole pellets: enhanced drug stability and oral bioavailability. AAPS PharmSciTech 2014;15:513-21.

13. Yoshida T, Lai TC, Kwon GS, Sako K. pH-and ion-sensitive polymers for drug delivery. Expert Opin Drug Delivery 2013;10:1497-513.

14. Palanisamy M, Khanam J. Cellulose-based matrix microspheres of prednisolone inclusion complex: preparation and characterization. AAPS PharmSciTech 2011;12:388-400.

15. Rajeshwar KK, Arya VJ, Ripudaman S. Development and evaluation of gastro-resistant microspheres of pantoprazole. Int J Pharm Pharm Sci 2010;2:112-6.

16. Comoglu T, Dogan A, Basci N. Development and in vitro evaluation of pantoprazole-loaded microspheres. Drug Delivery 2008;15:295-302.

17. Herrmann J, Bodmeier R. Biodegradable, somatostatin acetate containing microspheres prepared by various aqueous and 
non-aqueous solvent evaporation methods. Eur J Pharm Biopharm 1998;45:75-82.

18. Venkateswaramurthy N, Sambathkumar R, Vijayabaskaran M, Perumal P. Clarithromycin mucoadhesive microspheres for anti-helicobacter pylori therapy: formulation and in vitro evaluation. Int J Curr Pharm Res 2010;2:24-7.

19. Mahajan HS, Tatiya BV, Nerkar PP. Ondansetron loaded pectin based microspheres for nasal administration: In vitro and in vivo studies. Powder Technol 2012;221:168-76.

20. Patil SB, Sawant KK. Development, optimisation and in vitro evaluation of alginate mucoadhesive microspheres of carvedilol for nasal delivery. J Microencapsulation 2009; 26:432-43.

21. Gaur PK, Mishra S, Bajpai M. Formulation and evaluation of controlled-release of telmisartan microspheres: In vitro/in vivo study. J Food Drug Anal 2014;22:542-8.

22. Pandit V, Pai RS, Yadav V, Devi K, Surekha BB, Inamdar MN, et al. Pharmacokinetic and pharmacodynamic evaluation of floating microspheres of metformin hydrochloride. Drug Dev Ind Pharm 2013;39:117-27.

23. Sawant KK, Patel MH, Patel K. Cefdinir nanosuspension for improved oral bioavailability by media milling technique: formulation, characterization and in vitro-in vivo evaluations. Drug Dev Ind Pharm 2016;42:758-6.

24. Rathor S, Ram A. Porous microsphere of 5 flouru uracil: a tool for site-specific drug delivery in gastric cancer. Int J Curr Pharm Res 2011;3:38-42.

25. Mennini N, Furlanetto S, Cirri M, Mura P. Quality by design approach for developing chitosan-Ca-alginate microspheres for colon delivery of celecoxib-hydroxypropyl-b-cyclodextrin-PVP complex. Eur J Pharm Biopharm 2012;80:67-75.

26. Raffin RP, Colomé LM, Pohlmann AR, Guterres SS. Preparation, characterization, and in vivo anti-ulcer evaluation of pantoprazole-loaded microparticles. Eur J Pharm Biopharm 2006;63:198-204.

27. Singh S, Shanthi N, Mahato AK. Formulation and evaluation of metronidazole tableted microspheres for colon drug delivery. Asian J Pharm Clin Res 2016;9:398-403.

28. Patel KJ, Dharamsi A. Formulation development and optimisation of controlled release microspheres of Aceclofenac using response surface methodology. J Chem Pharm Res 2015;7:88-99.
29. Subbiah G, D sudheer K, B sandeep K, R Abhilash, P Shanthan B, Kvs $\mathrm{P}$, et al. Controlled release formulation and evaluation of idarubicin microsphere using biodegradable hydrophilic and hydrophobic polymer mixtures. Asian J Pharm Clin Res 2010;3:179-82.

30. Pachuau L, Mazumder B. A study on the effects of different surfactants on Ethylcellulose microspheres. Int J PharmTech Res 2009;1:966-71.

31. Khare P, Jain SK. Influence of rheology of dispersion media in the preparation of polymeric microspheres through emulsification method. AAPS PharmSciTech 2009;10:1295-300.

32. Sharma M, Kohli S, Dinda A. In vitro and in vivo evaluation of repaglinide loaded floating microspheres prepared from different viscosity grades of HPMC polymer. Saudi Pharm J 2015;23:675-82.

33. Ahmed MM, El-Rasoul SA, Auda SH, Ibrahim MA. Emulsification/internal gelation as a method for preparation of diclofenac sodium-sodium alginate microparticles. Saudi Pharm J 2013;21:61-9.

34. Jelvehgari M, Hassanzadeh D, Kiafara F, Loveymia BD, Amiri S. Preparation and determination of drug-polymer interaction and in vitro release of mefenamic acid microspheres made of cellulose acetate phthalate and/or ethylcellulose polymers. Iran J Pharm Res 2011;10:457-67.

35. Deshmukh RK, Naik JB. The impact of preparation parameters on sustained release aceclofenac microspheres: a design of experiments. Adv Powder Technol 2015;26:244-52.

36. Patil S, Babbar A, Mathur R, Mishra A, Sawant K. Mucoadhesive chitosan microspheres of carvedilol for nasal administration. J Drug Targeting 2010;18:321-31.

37. http://www.usp.org/sites/default/files/usp_pdf/EN/USPNF/20 11-02-25711DISSOLUTION.pdf. [Last accessed on 25 Aug 2016]

38. Mostafa HF, Ibrahim MA, Mahrous GM, Sakr A. Assessment of the pharmaceutical quality of marketed enteric coated pantoprazole sodium sesquihydrate products. Saudi Pharm J 2011;19:123-7.

\section{How to cite this article}

- Krutika Sawant, Mitali Patel, Jiten Patel, Piyush Mundada. Formulation, optimization, characterization and in vivo anti-ulcer activity of esomeprazole magnesium trihydrate gastroresistant microspheres. Int J Pharm Pharm Sci 2017;9(1):273-282. 